\title{
La participación de las mujeres en la independencia hispanoamericana a través de los medios de comunicación
}

\author{
Ana Belén GARCía LÓPEZ \\ Licenciada en Historia de América - Historiadora \\ anabelen.garcia1@mpt.es
}

Recibido: $18 / 05 / 2011$

Aceptado: 27/07/2011

\begin{abstract}
Resumen
La mujer aprovechó los tiempos convulsos de la independencia hispanoamericana para intervenir en la lucha, transgrediendo las barreras sociales y pasando de ser un sujeto pasivo, circunscrito al espacio privado, a un sujeto activo, protagonista en el espacio público.

Sin embargo, este cambio fue sólo temporal, pues, aunque en la guerra su intervención fue aprovechada, en la paz, la prensa manipuló su participación, minimizando sus actuaciones, vilipendiando sus actitudes u olvidando su aportación, lo que queda mostrado en el artículo a través de varios ejemplos.

Palabras clave: Participación mujer; independencia; prensa

\section{Participation of women in Spanish American independence through the media}

Abstract

The woman took the troubled times of Spanish American independence to take part in the fighting, breaking the social barriers and going from being a inactive character, limited private space, to an active character, the protagonist in the public space.

However, this change was only temporary, because, although the war took advantage of his participation, the peace, the press manipulated her participation, minimizing her actions, insulting her attitudes or forgetting her contribution, showing in the article through several examples.
\end{abstract}

Key words: Participation woman; Independence; press

\section{Referencia normalizada}

García López, A. B. (2011). La participación de las mujeres en la independencia hispanoamericana a través de los medios de comunicación. Historia y Comunicación Social, Vol. 16, páginas 33-49.

Sumario: 1. Introducción. 2. Retrato en la prensa colonial de la situación social de la mujer.3. Muestras en la prensa de la participación de las mujeres en la Independencia. 3.1. Intervención femenina y cambio de rol. 3.2. Formas de participación y consecuencias. 4. Motivaciones de las mujeres y visión de la prensa. 5. Valoración de la actuación femenina en la Independencia. 5.1. Homenajes. 5.2. Desprecios y olvidos. 6. Conclusiones. Referencias bibliográficas

\section{Introducción}

Cuando aún resuenan los ecos de las celebraciones de los bicentenarios del inicio del proceso independentista del mundo hispanoamericano nos proponemos mostrar y valorar a través de los medios de comunicación la participación de la mujer americana en la independencia del continente. 
Este intento implica articular tres elementos: mujer, medios de comunicación e independencia, históricamente disociados por la correspondencia de los mismos a ámbitos distintos, ya que, mientras los medios de comunicación y el proceso independentista pertenecen al espacio público, la mujer estaba supeditada al ámbito privado.

Son múltiples los factores que explican la eclosión de los movimientos independentistas y las transformaciones experimentadas en los medios de comunicación y en el papel de la mujer en la sociedad.

El deterioro del régimen colonial, el malestar ante las reformas borbónicas del siglo XVIII, la propagación de los ideales libertarios de la Revolución Francesa, la influencia del proceso independentista de Norteamérica o la revolución de Haití, la prohibición de ocupar puestos políticos a los criollos o el vacío de poder producido en España por la prisión del rey y la invasión napoleónica, son algunas de las causas que provocaron el proceso independentista, iniciado en 1809 con los primeros gritos insurgentes y prolongado hasta avanzada la década de los años veinte.

De la misma forma se justifica la evolución de la prensa desde un nivel oficial, al servicio de los intereses de la Corona, constituida básicamente por noticias religiosas, administrativas, comerciales e informativas, propio de una etapa inicial (En 1722 aparece La Gaceta de México y Noticias de Nueva España, el primer periódico latinoamericano) hacia una prensa científica, cultural y literaria, influenciada por el espíritu renovador de la Ilustración, que constituyó el germen de la prensa patriótica de la fase independentista, de carácter político-panfletario.

Indudablemente, tanto en la transformación de la prensa como en el inicio de la independencia, fue clave la difusión de la traducción de los Derechos del Hombre y del Ciudadano, realizada en 1793 por Antonio Nariño, líder de la independencia de Colombia.

En lo referente a la libertad de prensa es muy significativo el artículo 11 de estos Derechos:

"La libre comunicación de los pensamientos y de las opiniones es uno de los derechos más preciosos del hombre: todo Ciudadano en su consecuencia puede hablar, escribir, imprimir libremente; debiendo sí responder de los abusos de esta libertad en los casos determinados por la ley"1

\section{Retrato en la prensa colonial de la situación social de la mujer}

Paralelamente se produjo la evolución del rol desempeñado por la mujer en la sociedad. La prensa colonial retrataba a la mujer de la época como hija, esposa, madre, vinculada siempre al hombre, reducida al espacio privado.

"Que el hombre aspire a la libertad y la mujer a las buenas costumbres. ¿Y en qué consisten las buenas costumbres? En obedecer" 2

Conforme a esta concepción se crearon varios estereotipos de mujer en función de la clase social, íntimamente asociada a la etnia. 
Así lo particularmente resaltable en la mujer criolla era la belleza y la vestimenta, mientras que en la mujer negra y mulata era su falta de moralidad y su rol como amas de leche, ocupadas en la crianza de los niños en sus primeros años, así como su condición de criadas, sirvientas o esclavas domésticas. Estas atribuciones eran compartidas con las indígenas dedicadas al servicio doméstico en múltiples modalidades.

Más allá de las diferencias, todas ellas compartían un factor común: la subordinación al hombre, la carencia de personalidad civil o política y la exclusión del espacio público pues se entendía que no tenían la capacidad para ejercer derechos como ciudadanas y debían dedicarse a las tareas que la naturaleza imponía a su género.

La Gaceta limeña se expresaba en este sentido:

"Nacidas para suavizar las costumbres del hombre, no deben tomar una parte activa en las discusiones, cuyo ardor es incompatible con la ponderación y dulzura que forman el embeleso de su sexo" 3

En su destino sólo cabían dos opciones: el matrimonio o el convento.

En el primero la mujer se subordinaba a la voluntad del marido, siguiendo la máxima de "El marido dispone y la mujer obedece". Su objetivo como mujer casada, conforme a la tradición cristiana, era dedicarse a las tareas del hogar, desarrollar su facultad de convertirse en madre y procurar la felicidad y el bienestar de su marido e hijos.

La mujer soltera era portadora de una imagen negativa, objeto de compasión y lástima, salvo las dedicadas a la vida religiosa, convertidas en ideales del estereotipo de mujer piadosa, consagrada al servicio religioso.

Sobre las mujeres de mala vida y las mendigas se aconsejaba la reclusión para preservar las buenas costumbres.

\section{Muestras en la prensa de la participación de las mujeres en la Independencia}

\subsection{Intervención femenina y cambio de rol}

Esta situación que relegaba a las mujeres a meros sujetos pasivos, marginadas del espacio público y ausentes de la participación política, fue sacudida por las nuevas ideas y los avatares de los movimientos emancipadores.

Así lo reflejaba la prensa de este período, convirtiéndolas en objeto de sus contenidos, bien exhortando su participación aprovechando su capacidad a favor de la causa o criticándolas despiadadamente por su comportamiento poco femenino, contrario a la imagen recogida y recatada del ideal femenino.

En esta línea se expresaba el general realista Pezuela, calificando la acción de las mujeres en la revolución de La Paz como la prostitución de la religión y el pudor provocando la subversión total del orden social establecido. 
“... llegando a tal extremo que las mujeres tomaron el más colorado partido, abandonaron la religión, prostituyeron el pudor, y finalmente vivieron con el mayor desenfreno hasta el 11 de octubre" 4

Las convocatorias a la incorporación femenina a la lucha para liberarse del poder español se difunden en la prensa de todo el continente.

En 1812, desde varios diarios insurgentes de la Nueva España se solicita a las mujeres que no se casen con españoles y en el supuesto de que lo hagan se les insta a que condicionen el matrimonio al paso de aquellos al bando insurgente. Se les pide también que eduquen a sus hijos a favor de la causa independentista.

En el caso de las mujeres casadas con españoles se les sugiere que se conviertan en espías a favor de la causa insurgente.

No solo en la prensa se exhorta a un comportamiento solidario con la revolución independentista, sino también en las canciones divulgadas entre el pueblo, como el llamamiento recogido en un corrido insurgente anónimo de 1812.

"A la guerra americanas / vamos con espadas crueles / a darle muerte a Callejas / y a ver al señor Morelos" 5

Aunque la mujer estaba excluida del periodismo como medio público que era, cuando la lucha hace necesaria la colaboración de todos, los hábitos cambian y ella aprovecha la coyuntura para expresar sus ideas.

Ya en el editorial del primer número de la Gaceta de Caracas (24 de octubre de 1808), su redactor jefe, Andrés Bello, llamó a las mujeres a colaborar en la publicación.

\footnotetext{
"Se suplica por tanto a todos los Sujetos y Señoras, que por sus luces e inclinación se hallen en estado de contribuir a la instrucción pública, y a la inocente recreación que proporciona la literatura amena, ocurran con sus producciones, en prosa o verso, a la oficina de la imprenta, situada en la Calle de la Catedral, del lado opuesto a la Posada del Ángel; y se ofrece corresponder a este favor empleando el mayor cuidado y prontitud en el despacho"6
}

Se encuentran en los periódicos insurgentes manifiestos de mujeres que prueban su implicación en el proyecto independentista y sus aspiraciones a ocupar un lugar en el espacio público.

Una de las evidencias de esta actitud aparece en la Gaceta de Caracas en 1811, donde se reproduce un documento firmado por un grupo de mujeres de la provincia de Barinas, en Venezuela, titulado "La Representación que hace el bello sexo al Gobierno de Barinas" (5 de noviembre de 1811), donde se ofrecen para defender la ciudad del asedio realista y para alistarse en el ejército republicano:

"El sexo femenino, Señor, no teme los horrores de la guerra: el estallido del cañón no hará más que alentarle: su fuego encenderá el deseo de libertad, que sostendrá a toda costa en obsequio del suelo Patrio. En esa virtud y deseando alistarse en el servicio para suplir el defecto de los militares que han partido a San Fernando, suplican a V.E. 
se sirva tenerlas presente y destinarlas a donde le parezca conveniente bajo el supuesto de que no omitirán sacrificios que conciernan a la seguridad y defensa" 7

Aunque el ofrecimiento fue rechazado, el hecho de haber publicado el manifiesto en la Gaceta de Caracas implica un ejemplo para otras mujeres y una afirmación de que la debilidad atribuida al sexo femenino no es obstáculo para la participación en la lucha.

Una de las mujeres que firmaron este manifiesto fue Josefa Camejo, destacada en la gesta independentista venezolana, incorporada desde sus inicios a la causa insurgente, en la que participó como soldado, mereciendo sus acciones la incorporación simbólica al Panteón Nacional Venezolano en el año 2002.

Tras permanecer 4 años en Nueva Granada, adonde llegó acompañando a las fuerzas del general Rafael Urdaneta en el éxodo emprendido por la población venezolana tras la derrota del primer intento independentista, regresó a Venezuela camuflada bajo ropajes harapientos para no ser descubierta y en 1821, disfrazada de hombre, al frente de 300 esclavos, provocó una rebelión contra las fuerzas realistas en la provincia de Coro que culminó con la liberación de dicha provincia del asedio realista.

\subsection{Formas de participación y consecuencias}

Son muchas las alusiones en la prensa coetánea al nuevo rol de la mujer en los tiempos convulsos de la independencia, manifestado en la participación en la actividad y compromiso políticos de múltiples y diversas formas: bien mediante la colaboración en actividades conspirativas, organizando en sus residencias reuniones y tertulias donde circulaba información proveniente de Europa y de las recién emancipadas colonias de América del Norte y se discutían las nuevas ideas políticas y se planeaban las acciones emancipadoras, bien a través de la actuación como espías valiéndose de su supuesta "debilidad" y "apatía política" (en un principio las mujeres eran vistas como criaturas inofensivas con total desinterés por los asuntos públicos por lo que los realistas no ocultaban sus planes en presencia de las mismas), como organizadoras de redes de información, en las que actuaban como correos proporcionando informes muy valiosos a los ejércitos patriotas que en muchas ocasiones salvaron sus vidas o determinaron sus victorias en los enfrentamientos bélicos, mediante la organización de protestas, la propagación de las ideas patriotas y la persuasión entre los ejércitos realistas (algunas fueron acusadas y hasta fusiladas por seducir a las tropas realistas para que se incorporasen al bando independentista), por la redacción de idearios y manifiestos, contribuyendo con la donación de dinero y joyas para la causa independentista, brindando refugio a los insurgentes, realizando el transporte de alimentos, ropas y material bélico, dedicándose a la reparación de armas, asumiendo el sustento familiar ante la ausencia de los hombres integrantes de las tropas insurgentes, con la presencia en los campamentos (troperas, rabonas, guareñas, soldaderas), ocupándose de la logística, acompañando a las tropas, preparando los avituallamientos, cocinando, atendiendo a los heridos, enterrando a los 
muertos, portando las armas, luchando como miembros de las guerrillas patriotas o como soldados en los campos de batalla, algunas vestidas de hombre para ser aceptadas en el combate, otras ejerciendo su condición de mujeres guerreras, desempeñando rangos militares e interviniendo como estrategas.

Las protagonistas de estas acciones pertenecían a todos los niveles sociales, desde las del pueblo, indígenas, negras y mestizas en su mayoría, hasta las criollas de las élites sociales. Todas contribuyeron en la medida de sus posibilidades y todas padecieron las consecuencias.

Muchas de ellas sufrieron las situaciones más adversas. En muchos casos fueron despojadas de todas sus posesiones, mediante la confiscación de sus bienes, propiedades y objetos personales, quedando sumidas en la pobreza. Algunas fueron condenadas al destierro, otras fueron perseguidas, sometidas a la denostación verbal en la prensa o al escarnio público; en muchas ocasiones recluidas en hogares, en conventos o en las prisiones, sufriendo torturas y vejaciones, y en otras, condenadas a muerte, bien fusiladas, ahorcadas o asesinadas de la manera más cruel.

\section{Motivaciones de las mujeres y visión de la prensa}

Los motivos que las llevaron a romper las barreras y tomar las riendas de sus vidas a favor de la causa independentista son tan variados como las formas de participación. En algunos casos fueron las condiciones precarias de sus economías familiares las que las incitaron a actuar, en otros sus sentimientos patrióticos, el pensamiento influido por las nuevas ideas revolucionarias procedentes tanto de América como de Europa, el rechazo al orden colonial con la consabida discriminación racial y de clases, la rebeldía contra el orden social que relegaba a las mujeres a criaturas sin derechos, y en otros casos, la relación de parentesco o afectiva con los soldados insurgentes o los defensores de la causa independentista.

Es precisamente esta última causa la que, conseguida la independencia, se señaló en muchos de los diarios de la época para explicar la participación femenina en acontecimientos ajenos a la naturaleza de su género y justificar comportamientos transgresores y mal vistos por la sociedad tradicional de la época.

El ejemplo más significativo es el protagonizado por Lucas Alamán cuando en 1831 intentó minimizar la actuación de Leona Vicario durante la guerra, afirmando que al igual que otras mujeres, no había sido movida por verdadero patriotismo sino por amor a su marido.

Indignada, Leona se defendió en varias cartas publicadas en el diario $E l$ Federalista Mexicano, dirigiéndole entre otras las siguientes palabras:

"Mi objeto en querer desmentir la impostura de que mi patriotismo tuvo por origen el amor, no es otro que el muy justo deseo de que mi memoria no pase a mis nietos con la fea nota de haber sido yo una atronada que abandoné mi casa por seguir a un amante. Me parece inútil detenerme en probar a Ud. lo contrario, pues además de que en mi vindicación hay suficientes pruebas, todo México supo que mi fuga fue de una prisión, y que ésta no la originó el amor, sino el haberme apresado a un correo que mandaba yo a los antiguos patriotas. En la correspondencia apresada no apareció ninguna carta amatoria... 
“Confiese Ud. Sr. Alamán, que no sólo el amor es el móvil de las acciones de las mujeres: que ellas son capaces de todos los entusiasmos, y que los deseos de la gloria y de la libertad de la patria no les son unos sentimientos extraños; antes bien, suele obrar en ellas con más vigor, como que siempre los sacrificios de las mujeres son más desinteresados, y parece que no buscan más recompensa de ellos que la que sean aceptados. Si M. Staël atribuye algunas acciones de patriotismo en las mujeres a la pasión amorosa, esto no probará jamás que sean incapaces de ser patriotas, cuando el amor no las estimula a que lo sean. Por lo que a mi toca, sé decir que mis acciones y opiniones han sido siempre muy libres, nadie ha influido absolutamente en ellas, y en este punto he obrado siempre con total independencia, y sin atender a las opiniones que han tenido las personas que he estimado. Me persuado que así serán todas las mujeres exceptuando a las muy estúpidas, y a las que por efecto de su educación hayan contraído un hábito servil. De ambas clases también hay muchísimos hombres" 8

Leona Vicario, una de las mujeres más reconocidas en la guerra de la independencia mexicana, representa uno de los pocos ejemplos de participación activa de las mujeres en la prensa.

Hija de español y criolla, quedó huérfana muy joven, al cuidado de un tío defensor de la situación colonial; rebelándose contra la influencia familiar, esta intrépida mujer mostró desde los inicios de la independencia su libertad de pensamiento y su resolución de apoyar la causa patriota. Puso su fortuna heredada a disposición de la independencia, actuó como correo de los insurgentes informando de las acciones de los realistas, enviando mensajes en clave al periódico El Ilustrador Americano y ejerció como corresponsal de guerra informando de los acontecimientos en el campo de batalla, por lo que es considerada como la primera periodista de la historia de México.

Fue delatada, juzgada y al negarse a revelar los nombres de sus cómplices, recluida en el colegio de Belén, de donde fue rescatada por los insurgentes. Tras ello se casó con A. Quintana Roo, al lado del cual continuó la lucha, huyendo de un lugar a otro, hasta el punto de que tuvo a su hija en una cueva.

Conseguida la independencia, continuó con sus actividades políticas y periodísticas, escribiendo en el periódico El Federalista que se editaba gracias a sus recursos, siempre defendiendo sus ideales, como muestran las palabras que hemos reproducido anteriormente y que le dirigió al historiador conservador Lucas Alamán.

\section{Valoración de la actuación femenina en la Independencia.}

\subsection{Homenajes}

Es también Leona Vicario una de las pocas insurgentes que continúa una actividad pública tras la obtención de la independencia, pues en tiempos de paz, la actuación de las mujeres a favor de la misma fue olvidada y de nuevo fueron recluidas en sus hogares o en los conventos, pues las circunstancias excepcionales que justificaban la transgresión de las barreras de género habían desaparecido. 
Sólo se rindió homenaje a algunas, entre las que destaca Policarpa Salavarrieta, apodada como "La Pola", fusilada en Bogotá el 14 de noviembre de 1817.

Aunque muchas mujeres sufrieron un final idéntico, fue la única que mereció una mención en el Correo del Orinoco, periódico de la ciudad venezolana de Angostura, editado entre 1818 y 1822, y creado por Simón Bolívar como órgano propagandístico de la Tercera República venezolana, para contrarrestar la influencia de la Gaceta de Caracas, periódico al servicio de la Corona Española.

En la edición de 1 de enero de 1820 se publica el anagrama "Polycarpa Salavarrieta: Yace por salvar la patria", del colombiano Joaquín Monsalve, compañero de prisión de "La Pola".

La exaltación de patriotismo de los años posteriores al término del proceso independentista convirtió en un símbolo de valentía y coraje a esta mujer natural de Guaduas (virreinato de Nueva Granada), hija de Joaquín Salavarrieta, partícipe en el movimiento de los Comuneros en 1781 (levantamiento contra el régimen colonial extendido por el virreinato de Nueva Granada contra el incremento de impuestos que culminó con la represión y el ajusticiamiento de sus cabecillas), de la que se desconocen muchos de sus datos biográficos: su nombre (su padre la nombra como Polonia en el testamento, su hermano menor la llama Policarpa, pero todos la conocían con el sobrenombre de "La Pola"), su fecha de nacimiento (algunos la ubican en 1795 o 1796 , otros entre 1791 y 1796).

Lo cierto es que era la quinta de nueve hermanos y había quedado huérfana en 1802, a causa de la epidemia de viruela que asoló Santafé de Bogotá y provocó la muerte de sus padres y dos hermanos. Esta circunstancia la devuelve a Guaduas, su lugar de origen, junto a su hermana mayor y su hermano menor. Allí conoce el pasado como comunero de su padre e influenciada por las ideas insurgentes que recorren el virreinato, comienza junto a su hermano menor, Bibiano, su participación en la lucha independentista. En 1817 se trasladó a Santafé donde utilizó su ocupación como costurera en las casas de las señoras de los realistas para servir de espía, proporcionando información muy valiosa sobre el armamento y los movimientos realistas para preparar las emboscadas de los guerrilleros patriotas. También actuó de enlace de los revolucionarios, recibiendo y mandando mensajes de la guerrilla de los Llanos, compró material de guerra, convenció a los jóvenes para unirse a los grupos insurgentes, ayudó a desertar a muchos de ellos de las fuerzas realistas y participó en la fuga de los hermanos Almeida, caudillos que prepararon el levantamiento de los Llanos.

Esta última acción unida al arresto de su novio y colaborador, Alejo Sabaraín, descubrieron sus actividades y ocasionaron que fuese arrestada en 1817 y sentenciada a muerte junto con Sabaraín y otros patriotas.

En sus últimos días en prisión mostró su coraje y la convicción de sus ideales, encarando la muerte con un espíritu firme y entusiasta por la libertad. Así lo muestran las palabras que pronuncia cuando un soldado le ofreció un vaso de vino:

"Pueblo de Santafé ¿cómo permites que muera una paisana vuestra e inocente? Muero por defender los derechos de mi patria. Dios eterno, ved esta justicia”. 
O la exaltada arenga que dirigió al pueblo antes de ser ajusticiada:

“¡Pueblo indolente! ¡Cuán distinta sería hoy vuestra suerte si conociérais el precio de la libertad! Pero no es tarde. Ved que, mujer y joven, me sobra valor para sufrir la muerte y mil muertes más. ¡No olvidéis este ejemplo!”9

\subsection{Desprecios y olvidos}

En el extremo opuesto del enaltecimiento de "La Pola" se halla el tratamiento vejatorio dado en los medios de la época a las mujeres que irrumpieron en la escena política. Los casos más representativos son los de Francisca Zubiaga de Gamarra en Perú, Javiera Carrera en Chile o Manuela Sáenz en Ecuador.

Las tres fueron vilipendiadas, censuradas y exiliadas por ser mujeres transgresoras y haber invadido los tradicionales poderes del hombre. Se las tildó de egoístas, autoritarias, ambiciosas y dominantes, descalificándolas por utilizar las armas a su alcance para conseguir sus objetivos políticos mientras que se alababa la decisión de los caudillos, sus aspiraciones de grandeza y el empleo de cualquier método para hacer triunfar sus ideales.

Una vez más resurgió la subordinación a la que estaba sometida la mujer, dominada y no dominante, excluida además de la esfera pública, a la que se le permitió acceder solamente para colaborar en el triunfo del proceso independentista.

La primera de ellas, apodada de diversas formas, "La Mariscala", "La Presidenta", "La Pancha Gamarra" o "La Prefecta", fue entrevistada por la escritora feminista Flora Tristán cuando iba rumbo al exilio, lo que le permitió trazar un retrato de su personalidad en su libro "Peregrinaciones de una paria", ensalzándola como prototipo de mujer emancipada y transgresora y describiéndola con estas palabras:

"Como Napoleón, todo el imperio de su hermosura estaba en su mirada. ¡Cuánto orgullo! ¡Cuánto atrevimiento! ¡Cuánta penetración! ¡Con qué ascendiente irresistible imponía respeto, arrastraba voluntades y cautivaba la admiración! A quien Dios concede esa mirada no necesita de la palabra para gobernar a sus semejantes. Posee un poder de persuasión que se soporta y no se discute" 10

Pero no fueron estos los elogios que le dedicó la prensa peruana cuando tras distinguirse por su valor y dotes de mando en el campo de batalla, ejerció el poder político una vez conseguida la independencia.

Llegó a ejercer el poder a través de su matrimonio con el general cuzqueño Agustín Gamarra, el cual tras la consolidación de la independencia en Ayacucho en 1825, fue nombrado Prefecto del Cuzco por el mismo Bolívar.

A partir de entonces comenzó a mostrar sus dotes de mando y su carácter indomable, acompañando a su marido en dos expediciones al Alto Perú en 1828, en las que se adaptó perfectamente a la rudeza de la vida militar, destacando por su precisión en el tiro, el manejo ágil de la espada y su intrepidez como jinete. Pero fue un 
año después cuando se convierte en "La Mariscala", apodo que recibió al obtener Gamarra el grado de mariscal y acceder al gobierno del Perú, cuando mostró su determinación, arrojo y capacidad para tomar decisiones políticas.

Algunos episodios le reportaron la fama de soberbia, intolerante e implacable con sus enemigos tales como la orden de apalear a Juan Calorio, editor del diario opositor El Telégrafo de Lima o los azotes que ella misma propinó a un oficial edecán que se jactaba de haber merecido sus favores.

Otros evidenciaron que era una mujer de armas tomar, capaz de ejercer un poder de persuasión indiscutible. Ejemplo de ello es el lance acaecido una noche en que, informada de la sublevación en un cuartel porque la tropa no recibía su paga, se levantó de inmediato, tomó su cabalgadura y, vestida con uniforme militar, se presentó en el cuartel y con un látigo en una mano y una bolsa de dinero en la otra, se dirigió a los cabecillas, sus antiguos compañeros del ataque al pueblo boliviano de Paria, y les increpó:

$$
\text { “Cómo? ¿Ustedes mis cholos, contra mí?”11 }
$$

Los sublevados quedaron paralizados y en breve tiempo el motín quedó sofocado.

Esta decisión y capacidad de mando fue criticada por ser superior a la de su marido, por lo que la prensa limeña se expresaba en estos términos:

¡Habrá desvergüenza!

La mujer sólo manda en la cocina.

Fue acusada de neurótica y cruel, de marimacho, de mujer fácil, nombrándola "Cleopatra" por los numerosos amantes que se le adjudicaron.

En definitiva, su protagonismo en la cúpula del poder entre 1829 y 1833, reservada a los hombres y por tanto vedada a su género, le granjeó el repudio de la conservadora sociedad peruana surgida de la independencia y el destierro y exilio en Valparaíso donde murió el 8 de mayo de 1835 , víctima de la tuberculosis, pobre y en el anonimato.

Signo de los odios que despertó fue el ensañamiento difundido desde los diarios peruanos más conocidos El Telégrafo, El Convencional, El Playero y El Teniente cuando en 1834 cayó en desgracia y tuvo que abandonar Perú rumbo al exilio en Chile, publicando todo tipo de comentarios vejatorios.

Aquí yace la mujer más insolente que en los siglos el mundo hubo tenido otra más criminal jamás ha habido" 12

El editor de El Telégrafo, Juan Calorio, apaleado durante el gobierno de Francisca Zubiaga, revela así su repudio: 
“¡Venganza, venganza, claman las manos de las heroicas víctimas de Huaililachuco y Porongoche! ¡La Zubiaga esa hidra horrible que recorría el 28 de enero las rebeldes filas para excitarlas a la matanza del indefenso pueblo!" 13

El segundo ejemplo de mujer denunciada en los medios de comunicación coetáneos por haber ejercido un poder que no era inherente a su condición femenina fue la chilena Francisca Javiera Carrera y Verdugo, integrante de una familia que influyó decisivamente en la historia de Chile y cuya vida a su vez fue marcada por los avatares de la historia de su país.

Fue relegada por los cronistas al papel de mera colaboradora de sus hermanos y acusada de haber urdido el plan que provocó la muerte de sus hermanos. Creció en el seno de una familia de fortuna y linaje y en un ambiente intelectual donde se hablaba de los pensadores franceses que constituyeron sus primeras influencias ideológicas.

Fue el motor patriótico de su familia. El 4 de septiembre de 1810 estalló la revolución encabezada por su hermano José Miguel Carrera y Javiera representó el sector más radical, oponiéndose a los más moderados que se aferraban a la fórmula de gobernar en nombre de Fernando VII y defendiendo la necesidad de proclamar la independencia de la Corona española.

Desde diciembre de 1811 a octubre de 1814 los Carrera dominaron la política chilena. Javiera no ocupó ningún cargo político, pero actuó anónimamente en la esfera del poder. Fue asesora y consejera y su influencia fue incuestionable.

El revés del ejército patriota en Rancagua obligó a los hermanos Carrera a emigrar a Mendoza. Javiera los acompañó dejando en Chile a su marido y a sus hijos, lo que constituyó un motivo para que sus enemigos la acusasen de egoísta, caprichosa y desnaturalizada. Desde entonces padeció 10 años de destierro en tierras de Argentina y Uruguay donde llevó a cabo una intensa actividad política para conseguir volver a Chile y recuperar el poder político.

En 1817 San Martín, el general que había expulsado de Mendoza a los hermanos Carrera en el inicio de su exilio, consiguió en Chacabuco una importante victoria y en Chile O'Higgins, el enemigo acérrimo de Javiera y sus hermanos, fue nombrado Director Supremo inaugurando así la "Patria Nueva".

Los hermanos Carrera gestaron un complot para deponer al gobierno chileno y arrestar a San Martín, pero el intento falló y fueron arrestados Luis y Juan José, siendo fusilados en 1818, suerte idéntica a la que corrió su hermano José Miguel en 1821.

Javiera volvió a Chile tras la dimisión de O’Higgins. Abandonó la vida pública, repatrió los restos de sus hermanos en 1828 y se aisló en su hacienda de El Monte, recogiéndose en el espacio al que estaba predestinada por ser mujer.

Manuela Sáenz es el prototipo de mujer que no encajó en la moral patriótica de la sociedad que surgió tras la independencia en los recién nacidos países americanos y por ello fue agraviada y menospreciada, tildándola incluso de ser un defecto de Bolívar. 
Tanto los medios de comunicación coetáneos como la posterior historiografía oficial trataron de eclipsar su personalidad y minimizar su decisiva contribución a la independencia vinculándola siempre a la figura de Simón Bolívar, resaltando su relación sentimental como su único mérito.

Era una mujer de carácter recio y de voluntad inquebrantable, forjados desde su infancia, marcada por su condición de hija ilegítima de un hidalgo español y una criolla, de la que quedó huérfana a temprana edad.

Nació en 1797 en Quito, aunque su conciencia e identidad americanas se distinguieron tanto en sus palabras.

"Mi país es el continente de América. He nacido bajo la línea del Ecuador" 14

O en sus actos, puesto que contribuyó a la liberación de tres países: Ecuador, Perú y Colombia.

En 1817, siendo muy joven, contrajo un matrimonio de conveniencia, pactado por su padre, con el adinerado médico inglés James Thorne, 26 años mayor que ella. Con él se trasladó a Lima donde entabló amistad con la guayaquileña Rosa Campuzano (comprometida con la causa insurgente y conocida posteriormente como la amante del general San Martín) involucrándose ambas en la colaboración con los patriotas peruanos.

Desde 1819 Manuela asistió a reuniones, buscó recursos para financiar la causa patriota, actuó de espía, sirvió de correo y conspiró contra el gobierno colonial. Contribuyó decididamente en el cambio del batallón realista Numancia hacia las filas patriotas.

Por sus actividades proindependentistas, el general José de San Martín, tras tomar Lima y proclamar su independencia en julio de 1821, le concedió el título de "Caballeresa del Sol".

En los eventos de la entrada triunfal de Simón Bolívar a Quito el 16 de junio de 1822 , ve por primera vez al Libertador. Se convirtió en su amante y compañera de lucha durante 8 años hasta la muerte del libertador en 1830.

Se separó de su marido, enfrentándose a la hipocresía de la conservadora sociedad limeña que la acusó de comportamiento indecente, demostrando su autodeterminación y liberación de los prejuicios sociales.

Al año siguiente de conocerse, acompañó a Bolívar hasta Perú y estuvo a su lado en la mayoría de las campañas, participando activamente, hasta lograr la independencia.

Se incorporó al Estado mayor del general, haciéndose cargo de todo su archivo e interviniendo como consejera en los momentos difíciles del general; combatió en la batalla de Junín, consiguiendo por su valor el grado de Capitán de Húsares del Ejército Libertador y más tarde en la batalla de Ayacucho, bajo las órdenes de Antonio José de Sucre, quien le sugirió a Bolívar su ascenso a Coronela.

Muestra de su fuerte temperamento y coraje son las palabras que le dirige a Bolívar por la preocupación de éste ante la dureza de las jornadas que ha de soportar. 
"Mi amado: las condiciones adversas que se presenten en el camino de la campaña que usted piensa realizar, ni intimidan mi condición de mujer. Por el contrario, yo las reto". ${ }^{15}$

Cuando, tras la consecución de la independencia, se instaló con Bolívar en la ciudad de Santafé de Bogotá, éste fue objeto de dos intentos de asesinato, frustrados gracias a la valiente intervención de Manuela, reconocida desde entonces por el propio Bolívar como "La Libertadora del Libertador".

Con la renuncia de Bolívar a la presidencia de Colombia y su marcha hacia el exilio, Manuela continuó en Bogotá tejiendo intrigas políticas contra su principal enemigo el general Santander, lo que provocó que fuese vilipendiada por la prensa santanderista.

Tras la muerte del Libertador en 1830, temiendo su habilidad política y su capacidad de liderazgo, fue expulsada de Colombia. Partió hacia el exilio en la isla de Jamaica desde donde intentó regresar a su tierra en 1835, pero su pasaporte fue revocado por el presidente de Ecuador, Vicente Rocafuerte, por lo que decidió instalarse en el pueblo de Paita, al norte del Perú.

Durante los siguientes 25 años se dedicó a sobrevivir a través de la venta de tabaco, la traducción y escritura de cartas a los Estados Unidos de parte de los balleneros que pasaban por la zona, y la elaboración de bordados y dulces por encargo.

Continuó la defensa de Bolívar y no declinó su temperamento como testimonian las cartas escritas en este período a sus amigos.

A los 59 años murió víctima de una epidemia de difteria que azotó la región, el 23 de noviembre de 1856. Su cuerpo fue sepultado en una fosa común e incinerado.

Sólo a mediados del s. XX, un siglo después de su muerte, comenzaron a aparecer biografías y ensayos en los que se reivindicaba su verdadero papel en la independencia de las actuales Ecuador, Colombia y Perú.

A finales del s. XX Carlos Álvarez Saá, historiador de vocación, que defendió su imagen, rescató documentos originales, cartas y objetos personales y en 1994 creó en Quito un museo dedicado a su memoria.

El 22 de mayo de 2007, en el marco de la conmemoración de la batalla de Pichincha el presidente de Ecuador, Rafael Correa, le concedió el rango de Generala de la República de Ecuador.

\section{Conclusiones}

Trazado un somero retrato de algunas de estas mujeres y visto el tratamiento que recibieron en la prensa coetánea, resta subrayar las siguientes conclusiones:

Al margen del enfoque que se le ha aplicado en la prensa de la época a la actuación de las mujeres en esta etapa, hay suficientes evidencias para afirmar que las mujeres intervinieron decisivamente en los procesos independentistas que se desarrollaron en la América hispana.

Favorecidas por las circunstancias excepcionales de la guerra, las mujeres se convirtieron en sujetos activos, irrumpiendo en el espacio público y adquiriendo un protagonismo relevante, transgrediendo con su actitud y sus acciones las barreras que 
la sociedad imponía a su género. Si bien, este salto de la esfera privada a la pública fue temporal, pues una vez conseguida la independencia, la mayoría volvieron a recogerse en el espacio privado, el lugar que les reservaban los convencionalismos sociales.

Alcanzada la paz, su valiosa intervención fue presentada desde un discurso manipulador que silenció su papel destacado en el proceso, relegándolas a un nivel secundario, que minimizó su patriotismo atribuyendo los motivos de su implicación a razones sentimentales, negando su capacidad de pensamiento y decisión propios, que enalteció solamente las labores propias de su sexo, pero que denigró las actitudes y acciones de aquellas mujeres que se desenvolvieron en un ambiente masculino, que expresaron su pensamiento propio y reclamaron un protagonismo en la esfera pública, reservada a los hombres.

A pesar de su valiosa aportación, de haberse sacrificado y padecido los horrores de la guerra, no fueron tenidas en cuenta en la construcción de las nuevas repúblicas nacionales surgidas de la independencia.

Es tiempo ya, después de más de 200 años del inicio de aquel proceso, de rescatarlas de la ingratitud con la que fueron tratadas, de la invisibilidad a la que fueron relegadas.

\section{Referencias bibliográficas}

ALCIBÍADES, Mirla (2010). "Historia y trayectoria de la Gaceta de Caracas". En Cuadernos de Ilustración y Romanticismo. Revista Digital del Grupo de Estudios del Siglo XVIII. Universidad de Cádiz. № 16.

ÁLVAREZ SAÁ, Carlos (1995).“Carta de Manuela Sáenz al Libertador, 16 de junio de 1824". En Manuela, sus diarios perdidos y otros papeles. Quito: Imprenta Mariscal

AÑAZCO, Yolanda (2005). Manuela Sáenz, coronela de los ejércitos de la Patria Grande. Quito.

ARROM, Silvia Marina (1988). "La movilización de las mujeres". En Las mujeres de la Ciudad de México, 1790-1857. México: Siglo XXI

BERMÚDEZ GALLEGOS, Marta (1999). 'Poder y transgresión'. En Metáfora e Historia, Lima: Latinoamericana Editores.

COSTA DE LA TORRE, Arturo (1977). Mujeres en la independencia. La Paz: Ediciones Populares Última Hora.

GALÍA I BOADELLA, Montserrat (2002). Historias del bello sexo. La introducción del romanticismo en México. México: UNAM. Instituto de investigaciones estéticas.

GARCÍA, Genaro (1945). Leona Vicario: heroína insurgente. México D.F.: Secretaría de Educación Pública.

GUARDIA, Sara Beatriz \& GARCÍA, Juan Andreo (2002). Historia de las mujeres en América Latina. Murcia: Universidad. Fundación Seneca.

POMA MENDOZA, Vicente A. (2003). La coronela Manuela Sáenz A. Perfil: político, militar e ideológico y su sepultura en Paita. Quito: Agencia Editorial P\&C.

RIZO PATRÓN, Carlos Neuhaus, (1967). Pancha Gamarra, la mariscala. Lima: Ed. Francisco Moncloa S.A. 
TRISTAN, Flora (2003). Peregrinaciones de una paria. Lima: Centro de la Mujer Peruana. Universidad Nacional Mayor de San Marcos.

ULLOA INOSTROZA, Carla (2010). "Javiera Carrera Verdugo: aproximaciones al imaginario socio político de una mujer de la independencia y a su presencia en la historiografía chilena". En Anuario de Hojas de Warmi, no 15.

VALDIVIESO, Magdalena (2007). 'Las mujeres y la política fines del s. XVIII y comienzos del XIX en Venezuela', en Otras Miradas. Universidad de los Andes

VITALE, Luis (1987). La mitad invisible de la historia. El protagonismo social de la mujer latinoamericana. Buenos Aires: Editorial Sudamericana. Planeta.

\section{Referencias en Internet}

ÁLVAREZ SAÁ, Carlos. Manuelita Sáenz. Monografia. http://simonbolivar.org/Principal/bolivar/manuela_mono_menu.htm

COSTA TOSCANO, Ana María da. "Doña Francisca Gamarra más conocida como "la Mariscala" en Gloobalhoy n ${ }^{\circ} 5$.

http://www.gloobal.net/iepala/gloobal/fichas/ficha.php?id=912\&entidad=Ponencias \&html $=1$

GALEANA, Patricia (2007). "Lecciones de las mujeres de México del siglo XIX y asignaturas pendientes", Mujeres, Derechos y Sociedad. Enero del 2007, Año 3, No 5. Federación Mexicana de Universitarias A.C. http://www.mdemujer.org.mx/femu/revista/0305/0305art04/art04pdf.pdf

GÓMEZ, Andreína (1997), "Manuelita Sáenz. El enigma de una mujer 200 años después", en Diario el Nacional, 23 de febrero 1997, http://www.simonbolivar.org/Principal/bolivar/manuela_un_enigma.html

LOVERA DE SOLA, Roberto J., 'Cien mujeres y más'. En Palabra de Mujer. Caracas. http://palabrademujer.wordpress.com/2010/02/08/algunas-anotaciones-sobremujeres-venezolanas-siglos-xviii-xix/

PÉREZ GAY, Rafael, "La prensa insurgente”. http://www.eluniversal.com.mx/editoriales/49834.html

VIDAL, Virginia, (2010) "Perfil de doña Javiera Carrera". En Punto Final. Edición No 720, 15 de octubre, 2010. http://www.puntofinal.cl/720/Javiera_Carrera.php

VILLAMARÍN CARRASCAL, José. "Los primeros periódicos y la prensa insurgente en América Latina". En Sala de Prensa. http://www.saladeprensa.org/art655.htm

WEXLER, Berta, Las mujeres paceñas: una aproximación a su participación en el ejército revolucionario del siglo XIX ". Clio \& Asociados. La Historia Enseñada, N ${ }^{\circ} 5$. http://bibliotecavirtual.unl.edu.ar:8180/publicaciones/bitstream/1/2472/1/CLIO_5_2 000_pag_191_207.pdf

\section{Otros recursos en Internet}

'Encuentro con las heroínas de la patria', Caracas: Instituto Nacional de la Mujer, 2007.

"Las mujeres en la independencia de Chile. Portal de cultura chilena", www.memoriachilena.cl

"Policarpa Salavarrieta", www.biografiasyvidas.com/biografia/s/salavarrieta.htm 
http://www.venezuelatuya.com/biografias/

http://www.efemeridesvenezolanas.com $/ \mathrm{html} /$ josefa.htm

http://heroinasvenezolanas.tripod.com.ve/heroinasvenezolanas/id6.html

\section{Notas}

${ }^{1}$ Artículo 11 de la Declaración de los Derechos del Hombre y del Ciudadano, publicado en la Imprenta Patriótica el 15 de diciembre de 1793

2 Última carta de amor de C. Von Gunderrode a Bettina Brentano, en "Mujeres en América Latina". Universidad de Buenos Aires. Ministerio de Educación, Ciencia y Tecnología, p. 8

${ }^{3}$ La Gaceta de Lima, no 22, 11 junio 1794, p. 299

${ }^{4}$ Memoria 1813-1815. / WEXLER, Berta. Las mujeres paceñas: una aproximación a su participación en el ejército revolucionario del siglo XIX", Clío \& Asociados, La Historia Enseñada, $\mathrm{N}^{\mathrm{o}}$ 5. http://bibliotecavirtual.unl.edu.ar:8180/publicaciones/bitstream /1/2472/1/CLIO_5_2000_pag_191_207.pdf

${ }^{5}$ ARROM, Silvia Marina. (1988)“La movilización de las mujeres”. En Las mujeres de la Ciudad de México, 1790-1857, México: Siglo XXI, p. 52 / GALEANA, Patricia (2007). "Lecciones de las mujeres de México del siglo XIX y asignaturas pendientes". En Mujeres, Derechos y Sociedad. Enero del 2007, Año 3, $\mathrm{n}^{\circ} 5$ Federación Mexicana de Universitarias A.C. http://www.femumex.org/femu/revista/0305/0305art04/art04pdf.pdf

${ }^{6}$ Gaceta de Caracas, 24 de octubre de 1808

${ }^{7} \mathrm{Ibid}, 5 / 11 / 1811$

${ }^{8}$ Carta de Leona Vicario a Lucas Alamán, 26 de marzo de 1821, El Federalista Mexicano

9 Palabras pronunciadas por la Pola antes de ser fusilada. http://www.biografiasyvidas.com /biografia/s/salavarrieta.htm

${ }^{10}$ TRISTÁN, Flora (2003). Peregrinaciones de una Paria. Lima: Centro de la Mujer Peruana. Universidad Nacional Mayor de San Marcos, pp. 523-524.

${ }^{11}$ Cfr. RIZO PATRÓN, Carlos Neuhaus (1967). Pancha Gamarra, la mariscala. Lima: Ed. Francisco Moncloa, pp. 48-49.

${ }^{12} \mathrm{Ibid}, \mathrm{p} .117$

${ }^{13} \mathrm{Ibid}$, p. 116

${ }^{14}$ Declaración de Manuela Sáenz en carta pública publicado en el diario La Aurora de Bogotá, 1830. / GÓMEZ, Andreína (1997) "Manuelita Sáenz. El enigma de una mujer 200 años después". En el Diario el Nacional, 23 de febrero 1997. http://www.simonbolivar.org/Principal/bolivar/manuela_un_enigma.html

15 ÁLVAREZ SAÁ, Carlos (1995) "Carta de Manuela Sáenz al Libertador, 16 de junio de 1824”. En Manuela, sus diarios perdidos y otros papeles. Quito: Imprenta Mariscal, p. 79. 


\section{La autora}

Ana Belén García López es Licenciada en Historia de América, por la Universidad de Alcalá de Henares. Autora de Antonio Guzmán Blanco (Anaya. Colección Quinto Centenario. 1987), "Presencia de la mujer en las corporaciones municipales (19792003)". Revista El Consultor. 2007. Colaboradora de: Crónica de América (Editorial Plaza y Janés. 1990). Miembro fundador, coordinadora y ponente de "Tertulias Americanas" (2000-2011) y miembro colaborador de ACISAL.

Ponente en el Museo de América de Madrid, en La Casa de América dentro del II Encuentro Internacional Mujer e Independencia Iberoamericanas (2010) y en la Universidad Autónoma, en el Seminario de Mujeres Ilustres en la Historia (2011) con temas sobre la intervención de las mujeres en las independencias iberoamericanas.

Actualmente está realizando una investigación sobre la recuperación histórica de dicho tema. 